\title{
Ultra-high frequency induction welded process of reinforcement steel
}

\author{
P. Sari Çavdar* \\ Celal Bayar University, Vocational School, Department of Construction, Turgutlu Campus, 45400 Manisa, Turkey
}

Received 12 January 2015, received in revised form 25 February 2015, accepted 7 July 2015

\begin{abstract}
Induction welding is developing as an alternative method to welding processes. In this study, two different welding processes were applied. One of them was ultra-high frequency induction welding (UHFIW), the other was electrode welding (EW). Additionally, S420 reinforcement steels (RS) were rapidly welded by ultra-high frequency induction system using a current at a frequency of $900 \mathrm{kHz}$ and $2.8 \mathrm{~kW}$ power capacity. These steels are generally used in the construction of buildings. S420 RS were welded at $1100^{\circ} \mathrm{C}$ by induction for 5 min under an atmosphere environment. Alternatively, S420 RS were welded by the electrode. Mechanical properties and microhardness measurements were investigated for both processes. The results of the experimental studies were compared with each other.
\end{abstract}

K e y w o r d s: induction, reinforcement steel, welding, ultra-high frequency

\section{Introduction}

Construction and construction materials are the most important and popular fields of study nowadays. They have been popular in the past and will be far into the future as the human population increases day by day. As the population rises, so does the requirement for building constructions. Sand, cement and of course, reinforcement steels are the most important materials required.

Riberio et al. [1] studied the electrochemical behavior of carbon steel reinforcements under corrosion. Generally, in the chemical composition of S420 reinforcement steels, between 0.4 and $0.45 \mathrm{wt} . \%$ of the carbon is included. The weldability of the steel decreases with the increase of carbon content. $0.4 \mathrm{wt} . \%$ of carbon content is advised for the welding operations of the steels. In this work, S420 reinforcement steels were used for the welding application because these materials are the most widely used in construction applications.

Figeys et al. [2] reported that steel cord reinforced polymer (SCRP) can be used as external reinforcement. It consists of thin high-strength steel fibers embedded in a polymer matrix. In the literature [3-8], mainly the corrosion endurance of the reinforcement steel was investigated for construction, cerment, and chemical applications.

Induction is a rapid heating system. Generally, induction systems use forging [9] and heating applications [10-13]. In different studies, induction systems use sintering [14-17], welding [18-20], recycling [21] and hardening [22] applications because induction is one of the fastest heating processes in the world.

In this study, ultra-high frequency induction welding and electrode (electric arc) welding applications of the reinforcement steels were investigated. The mechanical properties and microhardness results were compared.

\section{Experimental study}

S420 reinforcement steels (RS) were used for both induction and electrode welding applications. The chemical composition of $\mathrm{RS}$ is given in Table 1 . The RS sizes are in TS_708, the Turkish standard. RSs were cut in $10 \mathrm{~cm}$ length pieces.

The RSs were welded by two different welding methods. One of them was induction welding; another

*Corresponding author: tel.: +90 53040762 00; fax: +90 236314 4566; e-mail address: pinar.sari@cbu.edu.tr 
Table 1. Chemical composition of S420 reinforcement steels

\begin{tabular}{cccc}
\hline$\% \mathrm{C}$ & $\% \mathrm{~S}$ & $\% \mathrm{P}$ & $\% \mathrm{Fe}$ (main materials) \\
\hline 0.40 & 0.05 & 0.05 & Balanced \\
\hline
\end{tabular}

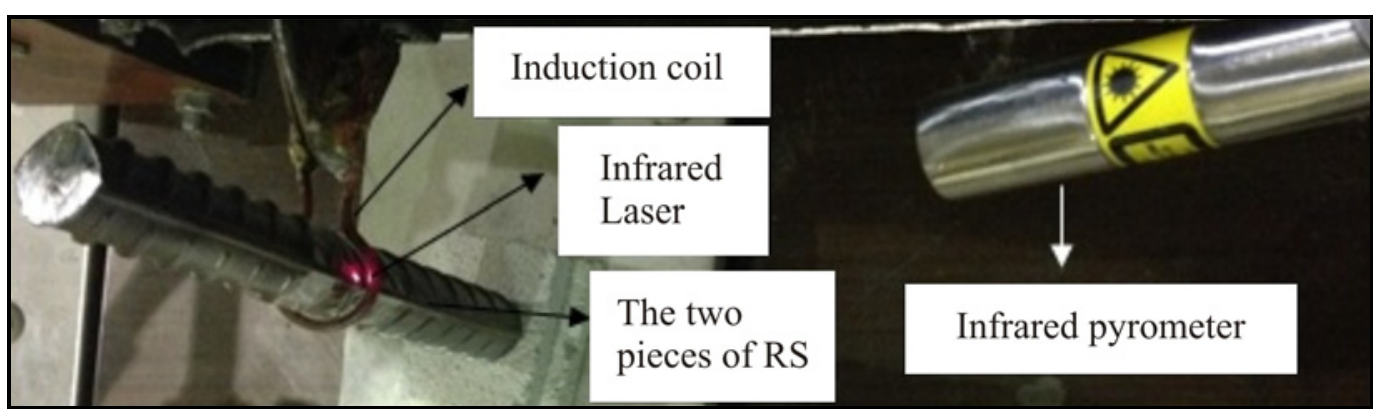

Fig. 1. UHFIW process of the reinforcement steel.

one was electrode welding. The RS samples were firstly cut into $10 \mathrm{~cm}$ lengths. In the induction welding operation of the RS, two steel pieces were welded by ultra-high frequency induction for $30 \mathrm{~min}$ at $1100^{\circ} \mathrm{C}$ under atmosphere environment. A cylindrical induction coil was used in the induction welding process of the RSs. The induction coil had a $4 \mathrm{~mm}$ diameter and a $0.5 \mathrm{~mm}$ wall thickness. The copper wire was wrapped once to build a coil with an inner diameter of $25 \mathrm{~mm}$. The cylindrical coil shape and welding process are displayed in Fig. 1. An infrared laser working in situ with the induction generator, measured and regulated $\left( \pm 5^{\circ} \mathrm{C}\right)$ the welding temperature of the induction system. The ultra-high frequency welding operation of the RS at $1100^{\circ} \mathrm{C}$ is shown in Fig. 2 .

In the electrode welding process, RSs were welded by the GEDIK POWER ARC 220 inverter electric arc welding machine under $10 \% \mathrm{H}_{2}$ and $90 \% \mathrm{~N}_{2}$ static atmosphere to protect compacts from the negative effect of air. Both welded samples were cooled naturally. The stages of the sintering and welding processes are shown as a flow chart in Fig. 3 .

Tension tests were applied on the welded samples using the Autograph Shimadzu AG-IS 100kN universal test machine. The microstructures of the welding regions were observed under a scanning electron microscope (JEOL SEM JSM-6060). Brinell hardness was measured from metallographically prepared surfaces of the welded and unwelded samples using universal microhardness test equipment (FUTURE TECH FM700) by loading $500 \mathrm{~g}$ of force for $15 \mathrm{~s}$.

\section{Results and discussion}

Three different conditions are discussed in this section. A $20 \mathrm{~cm}$ cut unwelded sample has been added to compare the mechanical properties of welding appli-

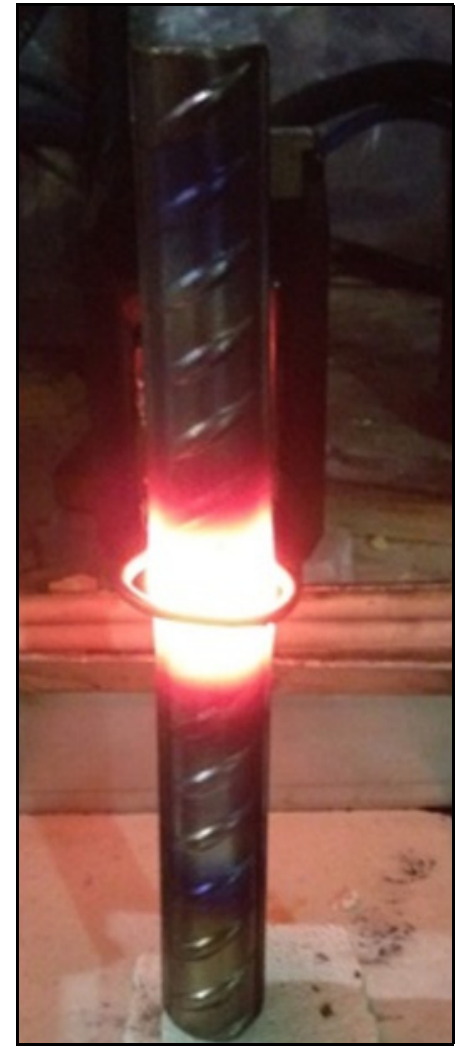

Fig. 2. Local induction welding operation of the RS.

cations. All of the sample images are shown in Fig. 4.

Enlarged images of the welded regions are given in Fig. 5. The UHFIW sample welded region is much more undeformed than the EW sample. The results of the tensile test are given in Table 2 .

In ref. [18], the authors reported that when the welding duration was increased from 2 to $5 \mathrm{~min}$, the bending strength of the samples also increased from 


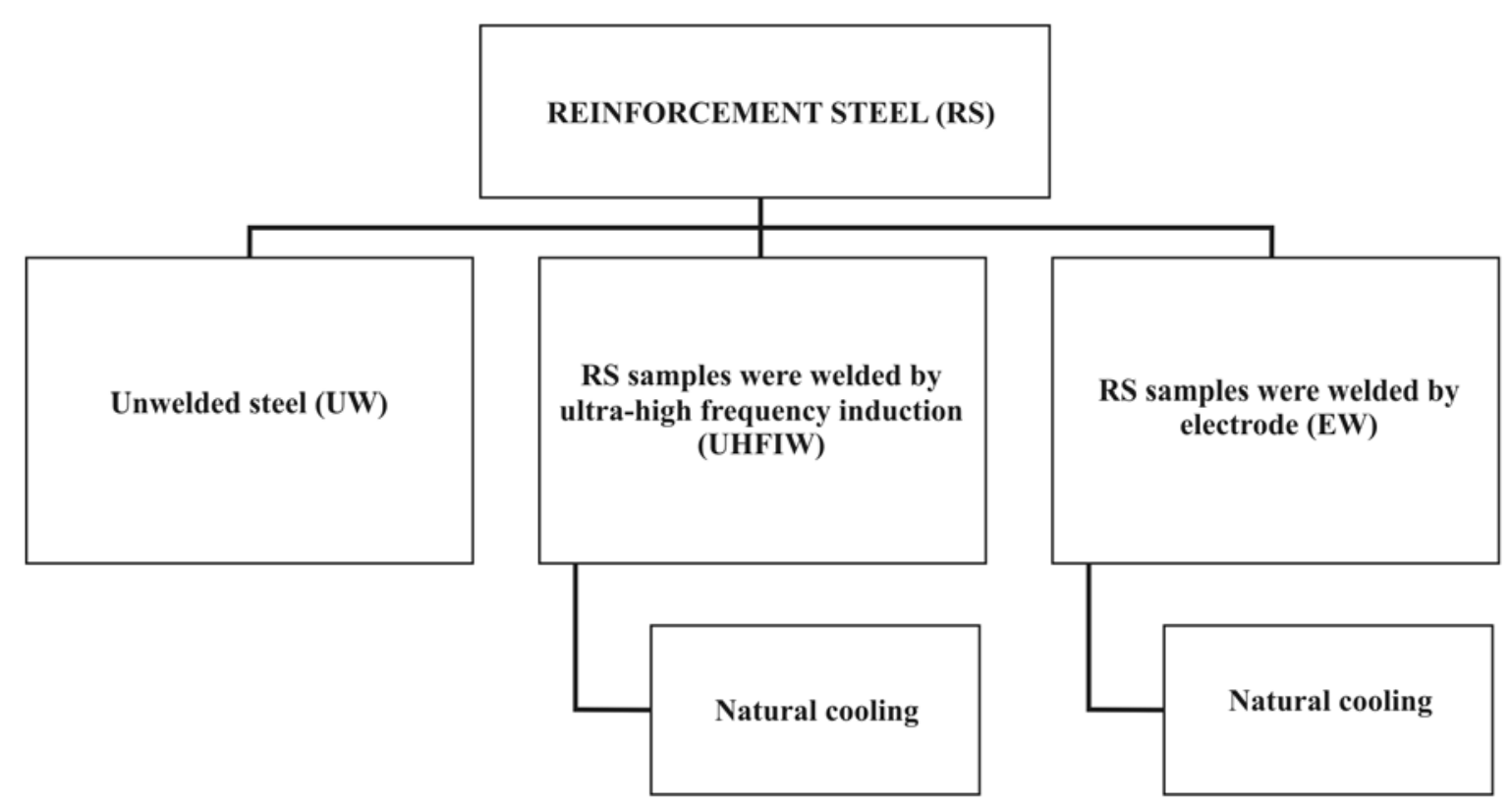

Fig. 3. Flow chart for the welding processes.

Table 2. Tensile test results

\begin{tabular}{lccc}
\hline Name of the samples & Code & Tensile strength $\left(\mathrm{N} \mathrm{mm}^{-2}\right)$ & Tensile strain (\%) \\
\hline Unwelded sample & UW & 458 & 9 \\
Ultra-high frequency induction welded sample & UHFIHW & 389 & 12 \\
\hline
\end{tabular}

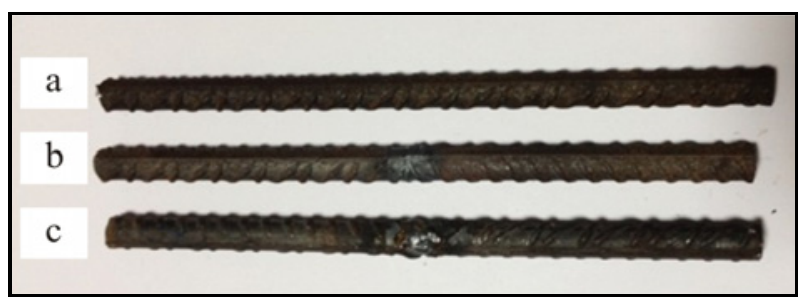

Fig. 4. a) Unwelded sample (UW), b) UHFIW sample, c) EW sample.

440 to $454 \mathrm{MPa}$. Furthermore, there is a significant difference in the bending strength of welded samples with polished surfaces and welded samples with unpolished surfaces. In contrast to the three point bending test results of the iron-based PM compacts, in this study, the tensile strength of the RS samples was investigated. According to the results, the unwelded sample tensile strength value $\left(458 \mathrm{~N} \mathrm{~mm}^{-2}\right)$ is the highest compared with the welded samples tensile strengths. The tensile strain values of UW and UHFIHW samples are very similar.

Microhardness results of the UW, UHFIHW, and EW are given in Fig. 6.

When comparing the hardness values measured

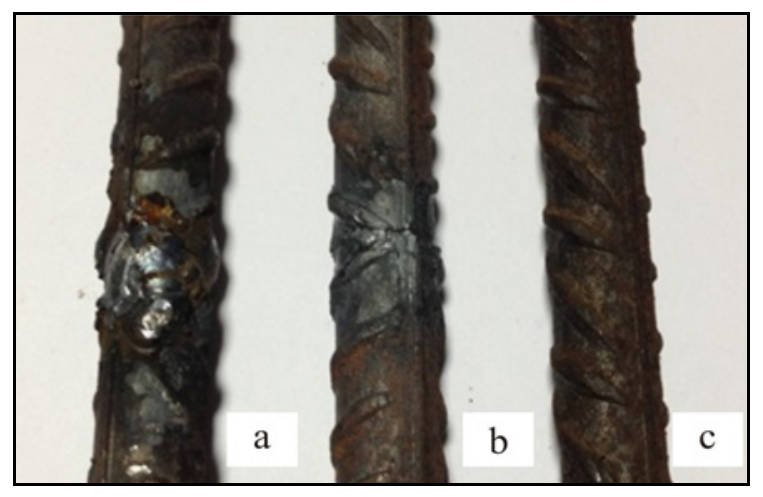

Fig. 5. a) EW sample, b) UHFIW sample, c) UW sample.

from the $5^{\text {th }}$ and $25^{\text {th }}$ points, which represents the welding zone of the EW and the UHFIHW as shown in Fig. 5, the highest hardness results were obtained from induction welded samples. Both welded sample welding zones were harder than the UW samples and the unwelded areas of the welded samples. Hardening occurred to the area exposed to heat, with the result of approximately $30 \%$ and $11 \%$ hardness increase, in the welded area of the UHFIHW and EW, respectively. 


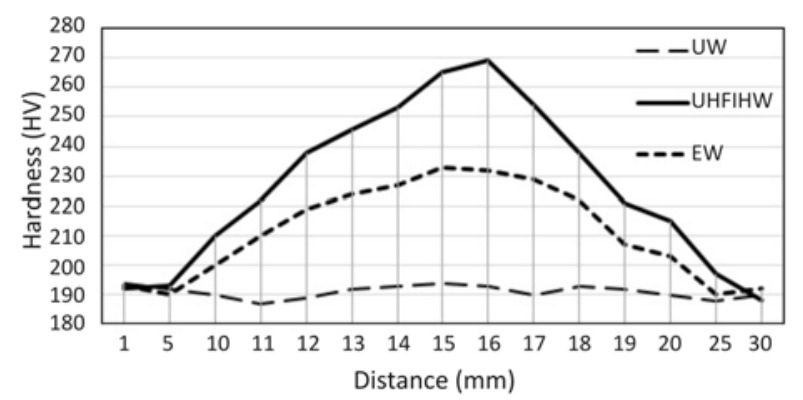

Fig. 6. HV microhardness versus measurement distance $(\mathrm{mm})$ graph for the samples.
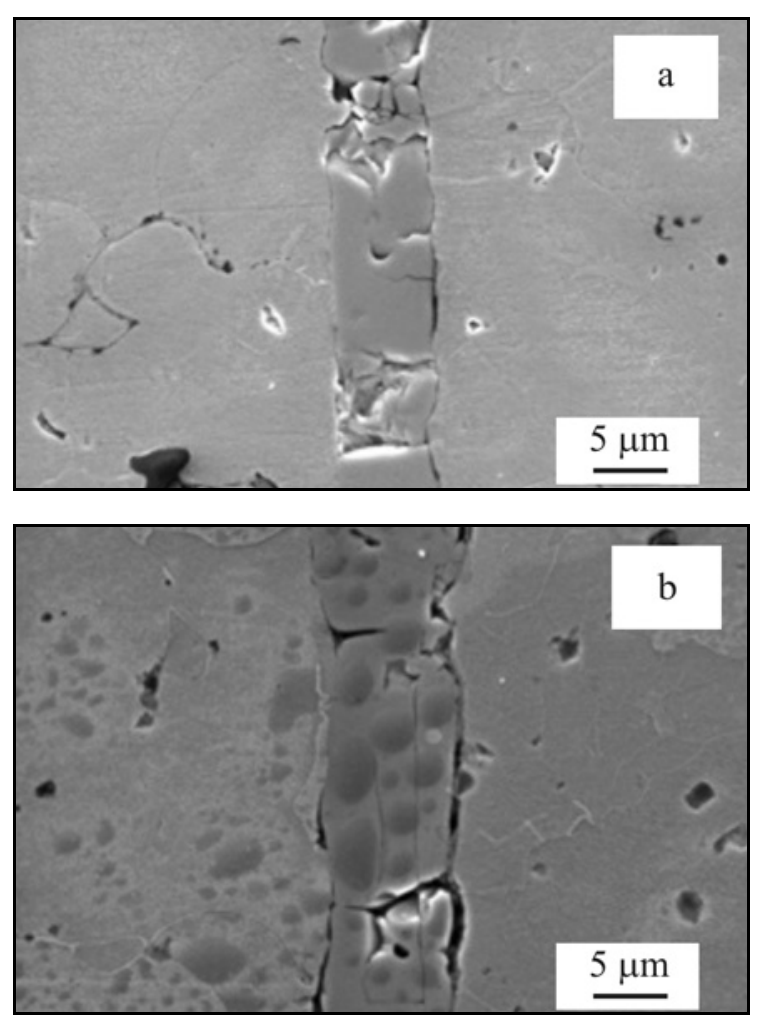

Fig. 7. SEM image of a) UHFIHW, b) EW.

Çavdar et al. [18] reported the hardness value of the 2 min welded iron-based powder metal (PM) compacts increased from $80 \mathrm{HBW}$ to $100 \mathrm{HBW}$, when the hardness was tested from the edge to the center of the sample. According to their results, the welding duration significantly increased the hardness of the material. The same effects were seen in this work. The hardness of the unwelded powder metal compact was about $80 \mathrm{HBW}$, alternatively, the 2 and 5 min welded PM compacts hardness values were $100 \mathrm{HBW}$ and 115 HBW. An approximately $20 \%$ and $28 \%$ increase in hardness occurred after the induction welding operations, respectively. More or less, the same hardness increase was seen in the welded area of the reinforcement steel (in the bulk material).

SEM images of the ultra-high frequency induction welding regions and electrode welding regions are shown in Figs. 7a,b. These layers were seen throughout all the welded areas. The thicknesses of the layers were measured by using image analysis with average results of 18 (for UHFIHW) and 25 (for EW) $\mu \mathrm{m}$. Bright regions indicating pearlite, and a few cementite lamellae were seen in the steels. The energy-dispersive X-ray spectroscopy (EDS) test was applied to the UHFIHW sample. The result of the EDS illustrated corrosion across this area showing oxidation occurred between the welded surfaces during the induction welding operation. Çavdar et al. [18] and Çavdar and Kusoğlu [19] reported that these oxidation layers were seen in the UHFIHW processes of the iron-based PM compacts. Polishing operations of the surfaces before welding improved the mechanical properties of the welded samples [18]. Induction coils also have an important role in the welding process [19].

\section{Conclusions}

Reinforced steels were welded successfully using an ultra high-frequency induction system and by using an electrical arc welding machine. The highest hardness and tensile strength values were obtained from the induction welded RS samples. The induction welding results illustrated that bulk steel materials could be welded by the ultra-high frequency induction welding system. The most important feature of this induction welding system is that it could be used for the fixing of reinforcement steels without damaging the wall of buildings.

\section{References}

[1] Ribeiro, J. L. S., Panossian, Z., Selmo, S. M. S.: Construction and Building Materials, 40, 2013, p. 40. doi:10.1016/i.conbuildmat.2012.09.097

[2] Figeys, W., Schueremans, L., Van Gemert, D., Brosens, K.: Construction and Building Materials, 22, 2008, p. 1929. doi:10.1016/j.conbuildmat.2007.07.006

[3] Pradhan, B.: Construction and Building Materials, 72, 2014, p. 398. doi:10.1016/j.conbuildmat.2014.09.026

[4] Fei, F. L., Hu, J., Wei, J. X., Yu, Q. J., Chen, Z. S.: Construction and Building Materials, 70, 2014, p. 43. doi:10.1016/j.conbuildmat.2014.07.082

[5] Ribeiro, J. L. S., Panossian, Z., Selmo, S. M. S.: Construction and Building Materials, 40, 2013, p. 40. doi:10.1016/j.conbuildmat.2012.09.097

[6] Ye, C. Q., Hu, R. G., Dong, S. G., Zhang, X. J., Hou, R. Q., Du, R. G., Lin, C. J., Pan, J. S.: Journal of Electroanalytical Chemistry, 688, 2013, p. 275. doi:10.1016/j.jelechem.2012.09.012

[7] Zhang, F., Pan, J., Lin, C.: Corrosion Science, 51, 2009, p. 2130. doi:10.1016/j.corsci.2009.05.044 
[8] Roventi, G., Bellezze, T., Giuliani, G., Conti, C.: Cement and Concrete Research, 65, 2014, p. 76. doi:10.1016/j.cemconres.2014.07.014

[9] Çavdar, U.: Materials Testing, 56, 2014, p. 258. doi:10.3139/120.110555

[10] Hauserová, D., Dlouhý, J., Nový, Z., Zrník, J.: Materiali in Tehnologije/Materials and Technology, 47, 2013, p. 701.

[11] Ayday, A., Durman, M.: Materiali in Tehnologije/Materials and Technology, 48, 2014, p. 787.

[12] Behulová, M., Masek, B., Meyer, L. W.: Kovove Mater., 48, 2010, p. 327.

[13] Razavi, G. R., Rizi, M. S., Zadeh, H. M.: Materiali in Tehnologije/Materials and Technology, 47, 2013, p. 611.

[14] Çavdar, U., Atik, E., Ataş, A.: Science of Sintering, 46, 2014, p. 195. doi:10.2298/SOS1402195C
[15] Çavdar, U., Atik, E., Akgül, M. B.: Powder Metallurgy and Metal Ceramics, 53, 2014, p. 191. doi:10.1007/s11106-014-9603-5

[16] Çavdar, U., Atik, E.: JOM, 66, 2014, p. 1027. doi:10.1007/s11837-014-0977-0

[17] Çavdar, U., Unlu, B. S., Atik, E.: Materiali in Tehnologije/Materials and Technology, 48, 2014, p. 977.

[18] Çavdar, U., Yalamaç, E., Gülşahin, I.: Materials Testing, 56, 2014, p. 852. doi:10.3139/120.110640

[19] Çavdar, U., Kuşoğlu, I. M.: Materials Testing, 56, 2014, p. 973. doi:10.3139/120.110641

[20] Çavdar, U., Gülşahin, I.: Revista de Metalurgia, 50, 2014, p. e016. doi:10.3989/revmetalm.016

[21] Torkar, M., Lamut, M. A.: Materiali in Tehnologije/ Materials and Technology, 44, 2010, p. 289.

[22] Sadeler, R., Sengul, A. B.: Kovove Mater., 44, 2006, p. 235 . 